\title{
The Teaching of Veterinary Surgery Medicine in Northwest A\&F University
}

\author{
De-Zhang Lu, Xin-Wu Ma, Yu-Hua Zhang, Ming Li \\ Department of Veterinary Surgery, College of Veterinary Medicine, Northwest A\&F University, \\ Yangling, China \\ Email: dezhanglu@hotmail.com
}

Received October $11^{\text {th }}$, 2012; revised November $15^{\text {th }}, 2012$; accepted November $28^{\text {th }}, 2012$

\begin{abstract}
Veterinary surgery medicine (VSM) is a core subject and important clinical discipline for undergraduate students of veterinary science. The present paper reviews current information about the teaching of VSM in Northwest A\&F University, presents a description of the veterinary science curriculum, suggests methods to improve the quality of VSM teaching in Northwest A\&F University, and describes difficulties, problems, and trends in veterinary education in Northwest A\&F University.
\end{abstract}

Keywords: Northwest A\&F University; Veterinary Surgery Medicine; Curriculum

\section{Introduction}

In order to judge the importance and value of teaching veterinary surgery medicine (VSM), there is a need to define what surgery is and hence what constitutes the teaching of VSM. For many people the term surgery equates with the physical procedure of operating. When one defines "Surgery" in narrow terms as Veterinary medical knowledge and techniques are interrelated throughout the world. However it is evident that the educational and training systems for veterinarians in each country are quite dissimilar when evaluated against each other.

This is the vision for Northwest A\&F University veterinary medical education system: that advancements be made towards serving the needs of society as well as a gradual transformation of veterinary programs to create efficient, knowledgeable, and qualified veterinarians for new generations.

Northwest A\&F University is a national key comprehensive university directly under the jurisdiction of Chinese Ministry of Education. The College of Veterinary Medicine is one of the traditional competitive colleges in Northwest A\&F University, whose history can track back to the Teaching and Research Section of Animal Husbandry and Veterinary Medicine in the National Northwest Junior College of Agriculture and Forestry founded in 1936 in the Yangling, Shanxi Province and was the first high level institution for modern agricultural education in northwest China. After more than 70 years' construction and development, the Faculty of Veterinary Medicine has formed a multi-level teaching system with undergraduate education as the main body and postgraduate education as the direction.

The first recognized veterinary school in China was established in 1910 in the Baoding, Hebei Province. Originally named as the "Farriery Division" its course of study was primarily based upon equine diseases due to the importance of horses as the means of transportation and communication in ancient China (Yin et al., 2006).

In the past decades, the teaching of veterinary surgery medicine at Northwest A\&F University curriculum has undergone considerable changes in quantity, mode and method of delivery. This is a result of the radical reforms of higher education, the health service and the veterinary medical curriculum. As part of its strategy for the years 2008-2013, the Faculty of Veterinary Medicine in Northwest A\&F University decided to carry out a comprehensive evaluation of its education and degree system during 2011-2013.

\section{Purpose and Requisite of VSM Teaching in Northwest A\&F University}

VSM (veterinary surgery medicine) is a combination of science and technical skill, and few would deny that education in both areas is critical to the proper development of a vet (Smeak, 2007). The pedagogical structure in Northwest A\&F University has students devoting much of their early professional education to developing a firm foundation of anatomy, histology, pathology, and the fundamental principles of surgery. When they approach their intensive practice, students to apply this knowledge as the basis for clinical problem solving, to form appropriate differential diagnoses, and to make proper management decisions about their sick animals.

VSM (veterinary surgery medicine) in Northwest A\&F University aims to ensure that students achieve the following objectives:

1) Comprehend VSM and gain theoretical knowledge of the damaging, surgical sepsis and other general surgical disease etc., but also special disease such as tumour, eyes disease, tooth disease, orthopedic and joint diseases etc;

2) Understand the mechanisms, clinical characteristics, diagnostic methods, examination techniques, therapies, and prevention approaches of the principal diseases of veterinary surgery;

3) Integrate theory and practice by using case teachings, such as clinical case explanations and causes of a particular disease, as much as possible.

\section{Delivery and Topics of VSM Courses in Northwest A\&F University}

VSM in Northwest A\&F University is usually taught in one semester of the fourth year in five-year veterinary science pro- 
grams. Students take about 72 lecture hours, including 56 theoretical teaching lecture hours devoted to theoretical teaching of VSM-related diseases, 16 experimental teaching lecture hours, and one week of intensive practice in university affiliated animal hospitals. In other countries, animal hospitals affiliated with universities always include a large-animal hospital, horse hospital, farm-animal hospital, and small-animal hospital (Smeak et al., 1991). But In Northwest A\&F University, two animal affiliated hospitals are mixed practices.

When a new subject is taught, the teacher gives a general introduction; discusses its importance; and focuses on common causes, clinical symptoms and signs, clinicopathology, methods of diagnosis, operation approach, treatment, and precautions. (see Tables 1 and 2). Domestic animals—such as cattle, horses, and pigs - are always treated as pathomodels in the past in China (Yin et al., 2006). In recent years, many diseases of small animals, such as dogs and cats, have been included. Cows and horses are seldom used due to their economic value. Experimental content usually follows the end of the corresponding subject, covering intensive fundamental knowledge and practical skills training. When the course is over, students are required to take part in a clinical practice course before the end of the semester in an animal hospital affiliated with the university to solidify their knowledge of VSM.

\section{Assessment of Students' Performance in VSM}

Northwest A\&F University establishes a protocol to assess a student's performance in VSM. Students undergo two examinations, once at the end of the semester, which account for
$60 \%$ of their final marks; the other at the end of the clinical practice course, which account for $20 \%$ of their final marks. In addition, students' performance in VSM accounts for another $20 \%$ of their final marks, and includes attendance and presentations of classroom. The end-of-semester examination usually covers the entire subject, but emphasis is placed on the more important aspects of VSM.

\section{Evolution of VSM Training}

VSM is much more of a global term and the teaching of VSM also includes learning about specific clinical conditions such as the acute abdomen, surgical emergencies such as gastric torsion and trauma, and gaining more exposure to seriously ill animals that may well require a surgical procedure (Griffon et al., 2000). Exposure to these conditions also trains the student's mind in careful, accurate assessment and rapid decision-making. Exposure to common "surgical" problems such as skin lesions, "lumps and bumps" and hernias can also be beneficial for the overall education of the student.

It is also important to recognize that surgical teaching is not restricted to the operating theatre (Agha et al., 2005). The students also see sick animals in clinic, where accompanying medical students can learn the generic skills of taking histories, doing clinical examinations and ordering the appropriate investtigations. Whilst a surgical rotation or environment is not the only place to gain such generic skills, it certainly does provide a good opportunity for their acquisition. Animal hospitals can form a good learning environment with animals often having clear histories and prominent physical signs (Burns et al. 2006).

Table 1.

Topics taught in VSM (veterinary surgery medicine) courses in Northwest A\&F University.

\begin{tabular}{cc}
\hline Chapter & Topics \\
\hline 1 & Overview of VSM: concept, task, contents, development, and how to study VSM \\
3 & Surgical trauma: wound, contusion, shock, ulcer, sinus, fistula, necrosis, gangrene \\
4 & Surgical infection: summary, Local infection, Systemic infection \\
5 & Tumor: summary, classification, etiology, epidemiology, diagnosis and therap \\
6 & Rheumatism, ophthalmopathy, otopathy, nasal disease, pharyngeal paralysis, dental diseases \\
7 & Cervical diseases, esophageal diseases and tracheal diseases \\
8 & Thoracic diseases, abdominal diseases and spinal diseases \\
9 & Hernia, urogenital diseases \\
10 & Extremities diseases \\
\end{tabular}

Table 2.

Experimental content in VSM (veterinary surgery medicine) courses in Northwest A\&F University.

\begin{tabular}{cl}
\hline Experiment & Topics \\
\hline 1 & Trauma: definition, etiopathogenesis, pathogenesis, clinical symptoms and signs, methods of diagnosis, treatment, and precautions \\
2 & Surgical infection: definition, etiopathogenesis, pathogenesis, clinical symptoms and signs, methods of diagnosis, treatment, and precautions \\
3 & Dental diseases: definition, etiopathogenesis, pathogenesis, clinical symptoms and signs, methods of diagnosis, treatment, and precautions \\
4 & Extremities diseases: pathogenesis, clinical symptoms and signs, methods of diagnosis, treatment, and precautions of both \\
5 & Dermatosis: pathogenesis, clinical symptoms and signs, methods of diagnosis, treatment, and precautions of both \\
\hline
\end{tabular}


Students also have the opportunity to build on their communication skills and learn how to explain complex procedures and prognosis as well as gain consent or break bad news empathetically and in a way the anxious or even depressed animals' owners can understand. This setting also improves a student's knowledge of the indications for a particular operation, the limitations of surgery as well as its curative value. Students have also been shown to gain significant knowledge and skills in this environment (Kogan et al., 2004).

The operating theatre in animal hospitals provides a unique educational experience for students, allowing for the integration and consolidation of knowledge. There is a need for students to observe normal and abnormal tissues as well as procedures directly in order to gain a true understanding of what is involved and how anatomy relates to pathology (Routly et al., 2002). Furthermore, the student will not have the opportunity to see such a wide variety of surgical procedures again once classroom are concluded. The concept of the multidisciplinary team also comes to life in the operating theatre, as the whole team is in the same room at the same time with the maintenance of a professional interaction for the benefit of the sick animals (Lyon, 2003).

Following conclusion of the operation, students may have the opportunity to learn about post-operative complications and the need for careful, regular observation and contingency planning. The criteria needed for discharge together with the decision-making skills involved are also developed to a fuller degree on a surgical firm (Reznick \& MacRae, 2006). The entire surgical spectrum from clinic to longterm follow-up provides the student with special insights into animals care and the opportunity at each stage to see the direct application of the principles of anatomy and physiology to clinical practice; each time relating the visible pathology and the clinical scenario to their background knowledge and understanding. Furthermore the student has the opportunity to consider with others the important ethical, moral, legal and psychosocial issues related to surgery including discussions on cost-benefit analysis which tend to be particularly acute in surgical practice (Polk, 1999).

\section{Difficulties of VSM Teaching in Northwest A\&F University}

With the adjustment of the policy of higher education, the health service and the veterinary medical curriculum to Northwest $A \& F$ University and the economic development of the past two decades, more students have the opportunity to complete a BVM (Bachelor of Veterinary Medicine) curriculum (there are approximately 180 students gain BVM in Northwest A\&F University every year). Although Northwest A\&F University has invested more financial support than ever before, there remain many difficulties and problems in teaching VSM. Some of the primary ones are outlined below.

\section{Shortage of Teaching Resources}

Currently in China, infectious diseases predominate in husbandry and cause large losses every year, and preventive veterinary medicine is regarded as extremely important. With the development of the economy, Chinese central and municipal governments have given increasing financial support to Northwest $A \& F$ University. Because clinical veterinary medicine is regarded as relatively unimportant, however, it is difficult to develop a large enough financial budget for clinical veterinary medicine teaching (Li et al., 2011). Sophisticated diagnostic tools such as two-dimensional echocardiography, laparoscopy, and magnetic resonance imaging are not used in VSM teaching in Northwest A\&F University because of economic reasons.

\section{Less Instruction Time for VSM}

In veterinary curricula, the instruction time for VSM (including classroom teaching and clinical practice) is much lower than that in other curricula, such as the veterinary microbiology and veterinary parasitology. This damages the quality of VSM teaching and has a negative impact on students' knowledge and skills.

\section{Lack of Enough Well-Qualified Teaching Staff}

Because it is difficult for VSM teachers to apply for research funding, is not considered to be a promising academic career. This frustrates young teachers devoted to teaching VSM. In order to earn money, VSM teachers engage in clinical veterinary medicine and concentrate on money, but doing so takes attention away from teaching and research.

\section{Trends in Teaching VIM in Northwest A\&F University}

Although there are many difficulties in the process, teachers have undertaken reform measures in teaching VSM in Northwest A\&F University in order to match the quality of teaching VSM in other areas of the world.

\section{Increasing Use of Multimedia Facilities}

Currently, multimedia facilities are being extensively used in teaching VSM in Northwest A\&F University. Web-based teaching offers students the opportunity to access teaching materials and feedback at any time as well as the advantage of the more vivid and direct presentation of subject matter (Dascanio, 2003).

\section{New VSM Subjects}

With developments in husbandry, some animal surgery diseases have become increasingly important ( $\mathrm{Li}$ et al., 2011). To cope with this change, new subjects those are relevant to VSM, such as orthopedic and joint diseases and animal dermatosis, have been developed as independent and elective disciplines in some developed countries.

\section{Updating the Content of VSM}

In the last century, VSM in China has focused on the diseases of Domestic animals - such as cattle, horses, and pigs, With the increasing number of companion animals such as dogs, cats, and birds, issues that are relevant to companion animals, shelter medicine, and welfare are now emphasized in VSM teaching.

\section{Future Considerations for Teaching VSM in Northwest A\&F University}

Problem-based learning (PBL) is well aligned and is thought to form an ideal learning environment encompassing the principles of learning in a practical way (Lane, 2008). Northwest 
A\&F University should move towards incorporating more prob- lem-based learning into our VSM curriculum and ensure that the curriculum prepares candidates well for the assessments. Students may not get fully involved in this form of teaching as it is further away from the traditional clinical environments of operative teaching. Northwest A\&F University must actively encourage the participation of students in their PBL programs.

In addition, we hope to provide more exposure to small animals' surgery at our VSM curricula, and conduct other common surgical procedures, if more funding for our reforms of VSM curricula. Because of the popularity of the surgery experience, opportunities for an additional week of this animal surgical experience are also being considered.

\section{Concluding Remarks}

Although there are many difficulties in teaching VSM, the quality of VSM education has greatly increased in Northwest A\&F University with the help of school, teachers and students' efforts. We understand that there is still a large gap between the quality of VSM teaching in Northwest A\&F University and that in most developed countries. China is a developing country and the developing Chinese economy provides options and opportunities for veterinary education. We believe that with the support of Chinese central and local governments and the painstaking efforts of Northwest A\&F University teachers and students engaged in VSM teaching, the quality of VSM teach- ing will improve dramatically in Northwest A\&F University.

\section{Acknowledgements}

This study supported by the Foundation for Talent of Northwest A\&F University (Grant No. Z109021110).

\section{REFERENCES}

Agha, R. A., Papanikitas, A., Baum, M., \& Benjamin, I. S. (2005). The teaching of surgery in the undergraduate curriculum. Part II: Importance and recommendations for change. International Journal of Surgery, 3, 151-157. doi:10.1016/j.ijsu.2005.03.016

Burns, G. A., Ruby, K. L., Debowes, R. M., Seaman, S. J., \& Brannan, J. K. (2006). Teaching non-technical (professional) competence in a veterinary school curriculum. Journal of Veterinary Medical Education, 33, 301-308. doi:10.3138/jvme.33.2.301

Dascanio, J. J. (2003). The use of information technology in large animal veterinary education. Journal of Veterinary Medical Education, 30, 326-330. doi:10.3138/jvme.30.4.326

Griffon, D. J., Cronin, P., Kirby, B., \& Cottrell, D. F. (2000). Evaluation of a hemostasis model for teaching ovariohysterectomy in veterinary surgery. Veterinary Surgery, 29, 309-316. doi:10.1053/jvet.2000.7541

Kogan, L. R., Butler, C. L., Lagoni, L. K., Brannan, J. K., McConnell, S. M., \& Harvey, A. M. (2004). Training in client relations and communication skills in veterinary medical curricula and usage after graduation. Journal of the American Veterinary Medical Association, 224, 504-507. doi:10.2460/javma.2004.224.504

Lane, E. A. (2008). Problem-based learning in veterinary education. Journal of Veterinary Medical Education, 35, 631-636. doi:10.3138/jvme.35.4.631

Li, J., Guo, D., Zhou, D., \& Wu, X. (2011). Teaching veterinary internal medicine in China. Journal of Veterinary Medical Education, 38, 194-198. doi:10.3138/jvme.38.2.194

Lyon, P. M. (2003). Making the most of learning in the operating theatre: Student strategies and curricular initiatives. Medical Education, 37, 680-688. doi:10.1046/j.1365-2923.2003.01583.x

Polk Jr., H. C. (1999). The declining interest in surgical careers, the primary care mirage, and concerns about contemporary undergraduate surgical education. The American Journal of Surgery, 178, 177 179.

Reznick, R. K., \& MacRae, H. (2006). Teaching surgical skillsChanges in the wind. The New England Journal of Medicine, 355, 2664-2669. doi:10.1056/NEJMra054785

Routly, J. E., Taylor, I. R., Turner, R., McKernan, E. J., \& Dobson, H. (2002). Support needs of veterinary surgeons during the first few years of practice: Perceptions of recent graduates and senior partners. Veterinary Record, 150, 167-171. doi:10.1136/vr.150.6.167

Smeak, D. D. (2007). Teaching surgery to the veterinary novice: The Ohio State University experience. Journal of Veterinary Medical Education, 34, 620-627. doi:10.3138/jvme.34.5.620

Smeak, D. D., Beck, M. L., Shaffer, C. A., \& Gregg, C. G. (1991). Evaluation of video tape and a simulator for instruction of basic surgical skills. Veterinary Surgery, 20, 30-36. doi:10.1111/i.1532-950X.1991.tb00302.x

Yin, J. C., Li, G. X., \& Ren, X. F. (2006). An overview of veterinary medical education in China: Current status, deficiencies, and strategy for improvement. Journal of Veterinary Medical Education, 33, 238243. doi:10.3138/jvme.33.2.238 